\title{
Ácidos graxos plasmáticos, metabolismo lipídico e lipoproteínas de ratos alimentados com óleo de palma e óleo de soja parcialmente hidrogenado
}

\author{
Plasma fatty acids, lipid metabolism and lipoproteins in \\ rats fed on palm oil and partially hydrogenated soybean oil
}

\author{
Ana Paula SILVA ${ }^{1}$ \\ Letícia NASCIMENTO ${ }^{1}$ \\ Fernanda OSSO ${ }^{1}$ \\ Daniella MIZURINI ${ }^{1}$ \\ Dilza CAMPOS ${ }^{1}$ \\ Ana Maria Blanco de MARTINEZ ${ }^{1}$ \\ Maria das Graças Tavares do CARMO $^{1}$
}

\section{RE S U M O}

\section{Objetivo}

Comparar, em ratos jovens, os efeitos metabólicos de dietas distintas, à base de óleo de palma e de gordura hidrogenada.

\section{Métodos}

Ratas Wistar receberam dietas com diferentes fontes lipídicas durante a lactação, as quais continuaram a ser dadas aos filhotes machos do $21^{\circ}$ dia ao 45 dia de vida, após ajuste às recomendações da American Institute of Nutrition-93, quando estes foram decapitados. Os tecidos adiposos epididimal e perirrenal foram retirados para determinação da taxa de lipogênese in vivo $\mathrm{com}^{3} \mathrm{H}_{2} \mathrm{O}$ e, no plasma, avaliou-se o perfil de ácidos graxos por cromatografia gasosa, além da concentração dos triacilgliceróis e colesterol total, por meio de kits enzimáticos.

\section{Resultados}

A substituição, na dieta, da gordura hidrogenada pelo óleo de palma aumentou, no plasma, a proporção do ácido graxo araquidônico e diminuiu a proporção do ácido essencial linolênico e a concentração dos triacilgliceróis e colesterol. Elevou o conteúdo lipídico e a taxa lipogênica do epidídimo e perirenal, repercutindo em maior peso corporal, bem como na adiposidade nesses animais.

\footnotetext{
1 Instituto de Nutrição Josué de Castro, Centro de Ciências da Saúde, Universidade Federal do Rio de Janeiro. Av. Brigadeiro Trompowisky, s/n, Bloco J, $2^{\circ}$ andar, 21941-590, Rio de Janeiro, RJ, Brasil. Correspondência para/Correspondence to: M.G.T. CARMO.E-mail: <tcarmo@editema.com.br>.
} 


\section{Conclusão}

O tipo de ácido graxo oferecido na dieta desde o período da lactação, pode influenciar o metabolismo lipídico do tecido adiposo na idade jovem, bem como o comportamento alimentar e ganho de peso corporal, com possíveis repercussões para o desenvolvimento de doenças crônicas não transmissíveis.

Termos de indexação: ácidos graxos trans, colesterol, óleo de palma, ratos, taxa de lipogênese.

\section{A B S T R A C T}

\section{Objective}

To compare the metabolic effects of diets based on palm oil and hydrogenated fat on young rats.

\section{Methods}

Wistar female rats, during lactation, were fed diets with different lipid sources, which were also adjusted to the recommendations (American Institute of Nutrition-93) and given to the male pups from the 21rst day to the 45th day of life, when they were killed. The epididimal and perirenal adipose tissues were extracted and had their lipogenesis rates measured in vivo with ${ }^{3} \mathrm{H}_{2} \mathrm{O}$. We also measured, in the plasma, the fatty acids profile, using gas cromatography, and the triglyceride and total cholesterol levels, using enzymatic kits.

\section{Results}

The replacement of dietary hydrogenated fat by palma oil, increased in the plasma the proportion of araquidonic fatty acid, and decreased the proportion of linolenic essential fatty acid, as well as the levels of triglyceride and total cholesterol. The lipid contents and the epidimal and perirenal lipogenic rates increased, resulting in higher body weight and adiposity.

\section{Conclusion}

The type of dietary fatty acid offered since the lactation period, can affect the lipid metabolism of the adipose tissue in early age, as well as the alimentary behavior and the gain of body weight, with possible repercussions on the development of non-transmissible chronic disease.

Indexing terms: trans fatty acids, development, cholesterol, palm oil, rats, lipogenesis rate.

\section{N T R O D U Ç Ã O}

Por volta da década de 60, em decorrência dos efeitos aterogênicos causados pelo consumo elevado de lipídios saturados, preconizou-se a substituição de grande parte dos ácidos graxos saturados da dieta, por ácidos graxos poliinsaturados e, conseqüentemente, a substituição da manteiga, pela margarina, e da banha, por óleos hidrogenados. No entanto, a margarina e os óleos vegetais parcialmente hidrogenados são fontes relevantes de ácidos graxos trans.

Estudos demonstram que as dietas à base dos isômeros trans aumentam a concentração plasmática da LDL, de maneira similar aos ácidos graxos saturados ${ }^{1}$, diminuem a concentração sanguínea de $\mathrm{HDL}^{2}$ e encontram-se mais associados às doenças cardiovasculares, quando comparadas a dietas à base de ácidos graxos saturados ${ }^{3}$. Os efeitos metabólicos dos ácidos graxos trans são pouco conhecidos. Sabe-se que estes ácidos graxos são absorvidos e incorporados aos tecidos, ligando-se às membranas nas posições freqüentemente ocupadas pelos ácidos graxos saturados ${ }^{2}$.

Estudos recentes mostraram efeito benéfico do óleo de palma, comparativamente a outras fontes lipídicas na dieta, em relação ao perfil lipídico sanguíneo ${ }^{4}$ e à diminuição de fenômenos relacionados à incidência de doenças coronarianas ${ }^{5}$. Muller et al. ${ }^{5}$ sugerem a substituição dos óleos hidrogenados pelo óleo de palma nos produtos alimentícios. Segundo estes autores, o óleo de palma, ao contrário do óleo de soja ou de outro óleo vegetal insaturado, não necessita de hidrogenação para atingir a consistência 
semelhante à da margarina, tornando-o isento de ácidos graxos trans.

Considerando que existem muitos questionamentos a respeito das respostas metabólicas que os lipídios podem desencadear no organismo, em especial os ácidos graxos trans, propusemos avaliar o metabolismo lipídico em filhotes de mães que receberam dietas distintas, à base de óleo de palma (OP) (óleo rico em ácidos graxos saturados - palmítico) ou de gordura hidrogenada (GH), durante a lactação, e cujos filhotes machos continuaram a receber as mesmas dietas até a fase jovem (45 dias).

\section{M É T O D O S}

Foram estudados ratos machos da linhagem Wistar procedentes do Biotério do Instituto de Nutrição da Universidade Federal do Rio de Janeiro UFRJ, obtidos logo após o parto. Durante o período da lactação, que teve duração de 21 dias, as mães receberam suas respectivas dietas com diferentes bases lipídicas, que continuaram a ser dadas aos respectivos filhotes após o desmame e durante todo o período do experimento. Após o desmame, os animais pesando em média 70 gramas, foram colocados em gaiolas coletivas e mantidos sob condições de ciclo de luz controlado ( 12 horas claro e 12 horas escuro) e temperatura constante $\left(24 \pm 1^{\circ} \mathrm{C}\right)$.

Eles foram divididos em dois grupos $(n=6)$ e alimentados com o seguinte esquema: Grupo Gordura Vegetal Hidrogenada (GH), formado por animais que receberam ração contendo $6 \%$ de gordura parcialmente hidrogenada e $1 \%$ de óleo de soja; Grupo Óleo de Palma (GP), formado por animais que receberam ração contendo $5 \%$ de óleo de palma e $2 \%$ de óleo de soja. O óleo de soja foi adicionado nas rações para adequá-las às necessidades de ácidos graxos essenciais. As dietas foram confeccionadas com base nas recomendações do American Institute of Nutrition ${ }^{6}$, tendo como ingredientes: caseína, amido, óleo de soja, óleo de palma, mistura de minerais,

Tabela 1. Composição percentual de ácidos graxos das dietas experimentais utilizadas por ratos machos até o $45^{\circ}$ dia de vida pós-natal.

\begin{tabular}{lcc}
\hline Ácidos Graxos (mg/g de dieta) & 5\% Óleo de Palma $+2 \%$ óleo de soja & $6 \%$ Gordura Hidrogenada $+1 \%$ óleo de soja \\
\hline C14:0 & 0,84 & 0,07 \\
C16:0 & 40,00 & 10,24 \\
C18:0 & 3,51 & 18,15 \\
C18:1 trans n-9 e n-7 isômeros & - & 14,12 \\
C18:1 (n-9) & 33,40 & 19,92 \\
C18:1 outros isômeros cis ${ }^{a}$ & 0,41 & 4,82 \\
C20:1 & 0,09 & 0,32 \\
C24:1 & - & 0,02 \\
C18:2 (n-6)tc & - & 0,17 \\
C18:2 (n-6)ct & - & 0,40 \\
C18:2 (n-6)tt & - & 0,12 \\
C18:3 (n-3)tb & 0,07 & 0,06 \\
C18:2 (n-6) & 21,18 & 20,75 \\
C18:3 (n-3) & 1,77 & 2,61 \\
Total ácidos graxos saturados & 44,35 & 28,46 \\
Total ácidos graxos monoinsaturados & 33,90 & 24,76 \\
Total ácidos graxos poliinsaturados & 23,64 & 23,36 \\
Trans ácidos graxos monoinsaturados & - & 14,12 \\
Trans ácidos graxos poliinsaturados & 0,07 & 0,68 \\
Soma dos trans & - & 14,80 \\
relação P/S & 0,53 & 0,82 \\
\hline
\end{tabular}

a inclui todos os isômeros cis de posição do $18: 1$, exceto o $18: 1(n-9) ; t=t r a n s ; c=c i s ; t=$ trans dupla; ${ }^{\mathbf{b}}$ mistura os isômeros geométricos mono-trans do 18:3 n-3. 
mistura de vitaminas, celulose, bitartarato de colina e 2 [6]-di-terc-butil-p-cresol (BHT) (Tabela 1).

A avaliação ponderal foi realizada durante todo o período experimental; os animais foram pesados em dias alternados, até a data do sacrifício, realizado por decapitação com guilhotina, no $45^{\circ}$ dia.

O sangue foi coletado no ato da de capitação, em frasco heparinizado ou EDTA (dependendo das análises bioquímicas), centrifugado, e o plasma foi armazenado a $-70^{\circ}$. O tecido adiposo epididimal foi retirado, pesado, devidamente embalado e etiquetado para posteriores análises. Em alíquotas de plasma, avaliamos a concentração de colesterol total e triacilgliceróis, usando kits enzimáticos fornecidos pela Katal Biotecnológica Indústria e Comércio Ltda.

A extração, saponificação e metilação dos ácidos graxos, foram realizadas de acordo com o método de Lepage \& Roy ${ }^{7}$. Os ésteres metílicos foram quantificados por cromatografia gasosa e os ácidos graxos separados com coluna capilar SP-2560 (Supelco Inc. Bellefonte, PA). Os ésteres foram identificados por comparação com seu tempo de retenção, com padrões conhecidos (Sigma, Supelco e Nuchek).

Para medida da taxa de lipogênese in vivo e percentual de lipídios no tecido adiposo epididimal e perirrenal, os animais foram injetados intraperitonealmente com $3 \mathrm{mCi}$ de ${ }^{3} \mathrm{H}_{2} \mathrm{O}$, contidos em $0,3 \mathrm{~mL}$ de água destilada; após 60 minutos foram sacrificados. O sangue foi coletado em frascos heparinizados, centrifugado e o plasma armazenado. Esse plasma ${ }^{8}$ foi utilizado para determinação da atividade específica da ${ }^{3} \mathrm{H}_{2} \mathrm{O}$. Fragmentos de $1 \mathrm{~g}$ dos respectivos tecidos foram colocados, em duplicatas, em tubos contendo $3 \mathrm{~mL}$ de $\mathrm{KOH} 30 \%$. Lipídios totais foram extraídos em éter de petróleo, pelo método de Stansbie et al. ${ }^{9}$

$O$ teste " $\mathrm{t}$ " de student para amostras independentes, foi usado para comparar as médias dos resultados obtidos entre os grupos, adotando o nível de significância de $p<0,05$.

\section{RES U L T A D O S}

Por meio da avaliação do peso corporal dos animais (expresso em gramas) de ambos os grupos, assim como do consumo alimentar (gramas/100g de peso corporal), pode se observar que, nos 45 dias de vida pós-natal, o grupo alimentado com dieta à base de óleo de palma, apresentou maior consumo alimentar (GP: $12,23 \pm 0,76 \mathrm{~g} / 100 \mathrm{~g}$ peso corporal) em relação ao grupo alimentado com dieta à base de gordura hidrogenada ( $\mathrm{GH}: 8,00 \pm 0,23 \mathrm{~g} / 100 \mathrm{~g}$ peso corporal) $(p<0,05)$; em conseqüência, foi significativamente maior o peso corporal do GP $(142,42 \pm 9,7 \mathrm{~g})$ em comparação ao do $\mathrm{GH}(107,0 \pm 10,0 \mathrm{~g})$ $(p<0,05)$.

Tabela 2. Peso (g) dos tecidos no $45^{\circ}$ dia de vida pós-natal de ratos alimentados com diferentes ácidos graxos.

\begin{tabular}{|c|c|c|c|c|c|c|}
\hline \multirow{2}{*}{ Tecidos } & \multicolumn{2}{|c|}{ Grupo gordura hidrogenada } & \multicolumn{2}{|c|}{ Grupo óleo de palma } & & \multirow{2}{*}{$\mathrm{T}(p)$} \\
\hline & M & EP & M & EP & & \\
\hline Coração & 0,79 & $\pm 0,01$ & 0,89 & $\pm 0,01 *$ & 7,07 & $(p<0,05) s$ \\
\hline Cérebro & 1,61 & $\pm 0,01$ & 1,62 & $\pm 0,04$ & 0,24 & $(p>0,05)$ ns \\
\hline Rins & 1,26 & $\pm 0,03$ & 1,69 & $\pm 0,03 *$ & 10,14 & $(p<0,05) s$ \\
\hline Fígado & 7,67 & $\pm 0,26$ & 7,76 & $\pm 0,28$ & 0,24 & $(p>0,05)$ ns \\
\hline Tecido Adiposo Epididimal & 1,34 & $\pm 0,04$ & 2,46 & $\pm 0,07^{*}$ & 13,89 & $(p<0,05) s$ \\
\hline Tecido Adiposo perirrenal & 0,31 & $\pm 0,01$ & 0,58 & $\pm 0,01 *$ & 19,09 & $(p<0,05) s$ \\
\hline Tecido Adiposo retroperitoenal & 0,89 & $\pm 0,04$ & 1,57 & $\pm 0,05^{*}$ & 10,61 & $(p<0,05) s$ \\
\hline
\end{tabular}

Os valores estão expressos como média \pm erro-padrão para 6 animais/grupo; * $p<0,05$ em relação ao grupo gordura hidrogenada; $\mathrm{s}=$ significativo; ns = não significativo. 
A Tabela 2 apresenta, para ambos os grupos, o peso dos tecidos - coração, cérebro, rins, fígado, tecidos adiposos epididimal, retroperitoneal e perirrenal - expresso em gramas. Observa-se que GH, o grupo que recebeu gordura hidrogenada, apresentou significativamente menor peso do coração, rins e dos tecidos adiposos brancos, em relação ao GP, grupo óleo de palma.

$\mathrm{Na}$ Tabela 3, estão representados os valores médios \pm EPM do conteúdo de gordura (g/100g) e da taxa lipogênica dos tecidos adiposos epididimal e perirrenal no $45^{\circ}$ dia de vida pós-natal. Podemos notar que o grupo que recebeu dieta à base de óleo de palma apresentou maior conteúdo lipídico $(p<0,05)$ e aumento da taxa de lipogênese $(p<0,05)$ nos tecidos adiposos. Este resultado sugere, portanto, que o aumento de peso corporal do GP seja decorrente da maior síntese de lipídios nos adipócitos.

Os resultados apresentados na Tabela 4 correspondem ao percentual de ácidos graxos no plasma de animais que receberam diferentes fontes de lipídios na dieta. Em relação à concentração de ácidos graxos saturados estudados, os valores percentuais de ácidos graxos C14:0; C15:0 e C16:0, assim como o somatório dos AGS, foram maiores para GP, que recebeu óleo de palma, em relação a GH. Entretanto, o GH apresentou maior percentual de cis isômeros, bem como de trans-AGM no plasma, em relação ao grupo que recebeu OP.

Avaliando os ácidos graxos poliinsaturados essenciais, observamos que houve uma diminuição significativa no percentual dos ácidos graxos linoléico e linolênico no plasma dos animais com dieta de OP, em comparação aos com dieta de $\mathrm{GH}$.

Os valores percentuais dos ácidos graxos poliinsaturados de cadeia longa, como C20:4 n-6 (AA); C20:5n-3 (EPA); C22:5 n-3, foram significativamente maiores no grupo que recebeu OP do que no grupo $\mathrm{GH}$.

No que se refere ao perfil lipoprotéico sangüineo, a concentração sérica de colesterol total foi significativamente maior no grupo $\mathrm{GH}$, que recebeu gordura vegetal hidrogenada, em relação ao grupo GP. Quanto aos valores de triacilgliceróis, estes também se apresentaram maiores no GH (Tabela 5).

\section{I S C U S S Ã O}

No presente estudo, a ingestão do óleo de palma durante a lactação, pela rata-mãe, e pelos filhotes machos até a idade jovem, ocasionou aumento gradativo no consumo alimentar; conse-

Tabela 3. Conteúdo lipídico $(\mathrm{g} / 100 \mathrm{~g})$ e taxa de lipogênese in vivo nos tecidos adiposos epididimal e perirrenal $\left(\mu \mathrm{mol}{ }^{3} \mathrm{H} 2 \mathrm{O}\right.$ incorporada em lipídios/g de tecido/hora) no $45^{\circ}$ dia de vida pós-natal de ratos alimentados com diferentes fontes de ácidos graxos dietéticos

\begin{tabular}{|c|c|c|c|c|c|}
\hline \multirow{2}{*}{ Tecidos } & \multicolumn{2}{|c|}{ Grupo gordura hidrogenada } & \multicolumn{2}{|c|}{ Grupo óleo de palma } & \multirow{2}{*}{$\mathrm{t}(p)$} \\
\hline & M & EP & M & EP & \\
\hline \multicolumn{6}{|l|}{ Tecido adiposo epididimal } \\
\hline Lipídios (g/100g) & 60,5 & $\pm 3,85$ & 69,77 & $\pm 1,22^{*}$ & $2,29(p<0,05) s$ \\
\hline $\begin{array}{l}\text { Taxa de lipogênese de } \mu \text { mol }{ }^{3} \mathrm{H} 2 \mathrm{O} \\
\text { incorporada em lipídios/g de tecido/hora }\end{array}$ & 31,2 & $\pm 2,65$ & 98,94 & $\pm 9,72$ * & $5,96(p<0,05) s$ \\
\hline \multicolumn{6}{|l|}{ Tecido adiposo perirrenal } \\
\hline \multicolumn{6}{|l|}{ Lipídios (g/100g) } \\
\hline Taxa de lipogênese de $\left(\mu \mathrm{mol}{ }^{3} \mathrm{H} 2 \mathrm{O}\right.$ & 49,2 & $\pm 1,67$ & 65,37 & $\pm 1,35^{*}$ & $7,35(p<0,05) s$ \\
\hline incorporada em lipídios/g de tecido/hora) & 28,4 & $\pm 2,29$ & 60,07 & $\pm 4,86^{*}$ & $5,27(p<0,05) s$ \\
\hline
\end{tabular}

Os valores expressos como média \pm erro-padrão; Número de animais/grupo =6; * $p<0,05$ em relação ao grupo gordura hidrogenada; $\mathrm{s}=$ significativo; $\mathrm{ns}=$ não significativo. 
Tabela 4. Efeito da ingestão de diferentes fontes lipídicas na dieta, sobre a composição percentual dos ácidos graxos no plasma de ratos jovens, no $45^{\circ}$ dia de vida.

\begin{tabular}{|c|c|c|c|c|}
\hline \multirow{2}{*}{ Ácidos graxos } & Grupo gordura hidrogenada & Grupo óleo de plasma & \multicolumn{2}{|r|}{$\mathrm{t}(p)$} \\
\hline & EP & EP & M & EP \\
\hline C 14:0 & $0,158 \pm 0,008$ & $0,204 \pm 0,007^{*}$ & 4,327 & $(p<0,05) s$ \\
\hline C15:0 & $0,186 \pm 0,010$ & $0,160 \pm 0,003^{*}$ & 2,490 & $(p<0,05) s$ \\
\hline C 16:0 & $22,830 \pm 0,380$ & $25,150 \pm 0,260 *$ & 5,038 & $(p<0,05) s$ \\
\hline C 18:0 & $8,250 \pm 0,190$ & $8,670 \pm 0,130$ & 1,824 & $(p>0,05)$ ns \\
\hline C18:1 (n-9) & $17,220 \pm 0,510$ & $19,080 \pm 0,770$ & 2,013 & $(p>0,05) \mathrm{ns}$ \\
\hline C18:1 outros cis isômeros ${ }^{a}$ & $3,280 \pm 0,180$ & $1,770 \pm 0,090 *$ & 7,503 & $(p<0,05) s$ \\
\hline C18:2 n-6 & $15,990 \pm 0,340$ & $10,610 \pm 0,350 *$ & 11,025 & $(p<0,05) s$ \\
\hline C18:3 n-6 & $0,286 \pm 0,020$ & $0,376 \pm 0,030 *$ & 2,496 & $(p<0,05) s$ \\
\hline C20:4 n-6 (AA) & $15,970 \pm 0,690$ & $22,490 \pm 0,600^{*}$ & 7,185 & $(p<0,05) s$ \\
\hline$C 22: 4 n-6$ & $0,378 \pm 0,005$ & $0,658 \pm 0,020^{*}$ & 13,581 & $(p<0,05) s$ \\
\hline C18:3 n-3 & $0,392 \pm 0,020$ & $0,326 \pm 0,010^{*}$ & 2,951 & $(p<0,05) s$ \\
\hline C20:5 n-3 (EPA) & $0,224 \pm 0,015$ & $0,346 \pm 0,020 *$ & 4,880 & $(p<0,05) s$ \\
\hline$C 22: 5 n-3$ & $0,346 \pm 0,015$ & $0,424 \pm 0,020 *$ & 3,120 & $(p<0,05) s$ \\
\hline C22:6 n-3 (DHA) & $1,970 \pm 0,065$ & $2,120 \pm 0,160$ & 0,868 & $(p>0,05)$ ns \\
\hline Total AGS & $31,420 \pm 0,450$ & $34,180 \pm 0,210^{*}$ & 5,638 & $(p<0,05) s$ \\
\hline Total AGM & $20,500 \pm 0,660$ & $20,850 \pm 0,780$ & 0,342 & $(p>0,05) \mathrm{ns}$ \\
\hline Total n-6 AGPI & $33,060 \pm 0,690$ & $34,610 \pm 0,730$ & 1,543 & $(p>0,05) \mathrm{ns}$ \\
\hline Total n-3 AGPI & $2,940 \pm 0,050$ & $3,216 \pm 0,140$ & 1,856 & $(p>0,05) \mathrm{ns}$ \\
\hline Total AGM- trans & $0,390 \pm 0,010$ & & & \\
\hline
\end{tabular}

Os valores estão expressos como média \pm erro-padrão para 6 animais por grupo; EPA = ácido graxo eicosapentaenóico; DHA = ácido graxo docosahexaenóico; $\mathrm{AA}$ = ácido graxo araquidônico. $\mathrm{s}$ = significativo; ns = não significativo; a inclui todos os isômeros cis de posição do 18:1 exceto o 18:1 (n-9); * $p<0,05$ em relação ao Grupo GVPH.

Tabela 5. Concentração de colesterol total $(\mathrm{mg} / \mathrm{dL})$ e triacilgliceróis $(\mathrm{mg} / \mathrm{dL}$ ) em ratos jovens ( 45 dias de vida) alimentados com dietas com diferentes tipos de ácidos graxos:

\begin{tabular}{lcrrr}
\hline \multirow{2}{*}{ Grupos } & \multicolumn{2}{c}{ Colesterol $(\mathrm{mg} / \mathrm{dL})$} & & \multicolumn{2}{c}{ Triacilgliceróis $(\mathrm{mg} / \mathrm{dL})$} \\
\cline { 2 - 3 } & $\mathrm{M}$ & $\mathrm{EP}$ & $\mathrm{M}$ & $\mathrm{EP}$ \\
\hline Grupos Gordura hidrogenada & $203,290 \pm 10,510$ & & $138,230 \pm 2,66$ \\
Óleo de palma & $166,27^{*} \pm \quad 8,670$ & & $98,45^{*} \pm 7,67$ \\
$\mathrm{~T}(p)$ & $2,717 \pm p<0,05 \mathrm{~s}$ & & $3,187 \pm p<0,05 \mathrm{~s}$ \\
\hline
\end{tabular}

Os valores estão expressos como média \pm erro-padrão para 6 animais por grupo. * $p<0,05$ em relação ao grupo gordura hidrogenada; $\mathrm{s}=$ significativo.

qüentemente, estes animais ganharam mais peso corporal, comparado ao grupo que recebeu dieta à base de gordura hidrogenada, rica em ácidos graxos trans.

É provável que as diferenças, observadas no consumo e peso corporal entre os grupos do presente estudo, sejam devidas à composição dos ácidos graxos, à relação $\mathrm{P} / \mathrm{S}$; à quantidade de ácidos graxos saturados e poliinsaturados e aos diferentes valores energéticos, já que os lipídios diferem em seu valor energético, conforme descrito por Khalil et al. ${ }^{10}$. Como o óleo de palma é digerido facilmente, absorvido e utilizado em processos metabólicos normais, é possível que sua eficiência metabólica também seja alta. A propósito, Hariharan et al. ${ }^{11}$ relatam a ocorrência de menor peso corporal em animais alimentados com dieta à base de óleo de palma.

Estas observações podem ser parcialmente explicadas pelas diferenças metodológicas do 
presente trabalho, em relação aos apresentados na literatura, especialmente no que se refere à duração do estudo, quantidade e qualidade de lipídios administrados e idade dos animais no início do estudo. Na maioria dos estudos com óleo de palma, presentes na literatura, as dietas são hiperlipídicas (>20\% de lipídios) e isentas da adição do óleo de soja, o qual promove a adequação dos ácidos graxos poliinsaturados essenciais. Este último aspecto é relevante, pois pesquisas já demostraram que a deficiência do ácido graxo essencial linolênico pode ocasionar diminuição na taxa de crescimento em ratos após o desmame ${ }^{12}$.

Em concordância com o maior peso corporal, o grupo que recebeu dieta a base de óleo de palma também apresentou maior peso do coração, rins e dos tecidos adiposos brancos (Tabela 2).

A Tabela 1 mostra a distribuição percentual dos ácidos graxos de cada uma das dietas do estudo. Como esperado na dieta com óleo de palma, os ácidos graxos mais abundantes são os ácidos graxos saturados, sendo o ácido graxo palmítico (C16:0) o que se apresenta em maior proporção, seguido dos ácidos graxos oléico (C18:1 n-9) e linoléico (C18:2 n-6). De maneira similar, nas dietas com gordura hidrogenada, os ácidos graxos saturados estão em maior proporção, porém em oposição à dieta $\mathrm{OP}$, a soma dos saturados se apresenta menor e o principal representante é o esteárico (C18:0), seguido do ácido graxo oléico (C18:1 n-9) e linoléico (C18:2 n-6). Cabe destacar a ausência do ácido araquidônico (C20:4 n-6) e do docosahexaenóico (C22-6 n-3) nas duas dietas utilizadas no estudo.

Quando avaliamos a distribuição percentual dos ácidos graxos da dieta (Tabela 1) e comparamos com a distribuição dos ácidos graxos encontrados no plasma (Tabela 4), observamos que a proporção de ácidos graxos plasmáticos difere substancialmente da dos incluídos nas dietas consumidas pelos animais. De modo que os dois grupos estudados apresentaram, no plasma, maior proporção dos ácidos graxos poliinsaturados, seguida pela dos saturados e monoinsaturados
(Tabela 4). É provável que isto decorra da liberação, pelos tecidos (principalmente hepático), para a circulação, dos ácidos graxos poliinsaturados de cadeia longa (AA, EPA e DHA), produzidos a partir da dessaturação e alongamento dos ácidos graxos essenciais.

Os ácidos graxos poliinsaturados de cadeia longa ( $A A, E P A$ e DHA), ainda que ausentes nas dietas, encontram-se de maneira apreciável no plasma e, especialmente, no daqueles animais com dieta a base de óleo de palma. O ácido araquidônico (AA) e o ácido docosahexaenóico (DHA) são sintetizados a partir dos ácidos linoléico e linolênico, respectivamente. Este processo é dado através de uma cascata de D-6 dessaturação, alongação e posterior dessaturação ${ }^{13}$.

Os animais alimentados com GH apresentaram valores mais baixos de AA e EPA; porém, apresentaram níveis mais altos dos ácidos graxos essenciais, linoléico e linolênico, comparados aos valores encontrados para o grupo que recebeu OP. Este fato pode ser consequência da inibição dos ácidos graxos trans na atividade da D-6 dessaturase; esta é uma enzima limitante na síntese dos ácidos graxos da série n-6, que pode ter sua atividade diminuída em função dos ácidos graxos trans, alterando a biossíntese dos ácidos graxos essenciais de cadeia longa ${ }^{14}$.

Apesar do ácido graxo esteárico (C18:0) entrar em maior proporção na dieta dos animais alimentados com GH, o ácido palmítico (C16:0), dentre os ácidos graxos saturados, foi o que se apresentou em maior abundância no plasma. Isto pode ser devido ao aporte de ácidos graxos derivados da síntese endógena, cujo produto final é o ácido palmítico (C16:0) e sua síntese, especialmente abundante no fígado ${ }^{15}$.

Pelo nosso conhecimento, este é o primeiro estudo que mostra os efeitos sobre o metabolismo lipídico do tecido adiposo branco, causados pelo consumo da gordura hidrogenada, e comparados aos do consumo do óleo de palma, desde a lactação até a fase jovem dos animais. Avaliando o efeito dessas diferentes dietas sobre o metabolismo dos tecidos adiposos epididimal (EPI) 
e perirrenal (PERI), observamos que a dieta OP elevou o peso do EPI e do PERI, acompanhado por aumento do conteúdo de gordura e pela síntese de ácidos graxos nesses tecidos (Tabelas 2 e 3). 0 mecanismo pelo qual o grupo OP induziu maior taxa de lipogênese no tecido adiposo branco, comparado ao grupo $\mathrm{GH}$, não pôde ser elucidado com os experimentos realizados neste estudo. No entanto, nossos dados demonstram que diferentes ácidos graxos em dietas normolipídicas conduzem também a diferentes efeitos no peso corporal e no metabolismo, visto que o grupo OP ganhou mais peso e gordura nos tecidos adiposos.

Vários estudos sugerem que os ácidos graxos dietéticos produzem significativos impactos nos níveis de lipídios circulantes. Atualmente, sabe-se que as gorduras que contêm C12:0 e C14:0 são, invariavelmente, mais hipercolesterolêmicas do que aquelas ricas em C16:0. As ricas em C16:0, são mais desfavoráveis em elevar a concentração de colesterol no sangue (exceto quando há ingestão concomitante de colesterol ${ }^{16}$ ), do que as gorduras ricas em ácido graxo esteárico $(C 18: 0)^{17}$, as quais promovem aumento da relação LDL/HDL no sangue ${ }^{18}$. Por outro lado, os ácidos graxos trans são mais hipercolesterolêmicos do que os seus correspondentes cis, ainda que menos hipercolesterolêmicos do que os $12: 0$ e o C14:019.

Nossos resultados demonstram que os lipídios dietéticos ricos em ácidos graxos trans e C18:0, presentes nas gorduras hidrogenadas, promovem significativamente maiores níveis de colesterol e triacilgliceróis, quando comparados às gorduras saturadas ricas em ácidos graxos palmíticos C16:0 (óleo de palma) (Tabela 5). Estes achados confirmam pesquisas anteriores de outros autores, os quais observaram efeitos benéficos do óleo de palma na redução dos níveis de lipídios circulantes ${ }^{20}$.

O mecanismo pelo qual o óleo de palma, apesar do seu alto conteúdo de C16:0, reduz os níveis de lipídios no sangue, não está elucidado, porém há várias hipóteses. A primeira deve-se à sua composição peculiar de ácidos graxos (observe- -se na Tabela 1), com cerca de $44 \%$ de ácidos graxos saturados e alta proporção de monoinsaturados (cerca de 34\%). Khosla \& Sundram ${ }^{17}$ sugerem que a ingestão de alimentos contendo ácidos graxos mono e poliinsaturados pode reduzir os níveis de LDL-colesterol no sangue, diminuindo assim o risco do aparecimento de doenças cardiovasculares. No presente estudo, a maior concentração de ácidos graxos poliinsaturados n-6 (>20\%) na dieta, foi decorrente da adição do óleo de soja, com a finalidade de aumentar o aporte de ácidos graxos essenciais. A segunda hipótese para a ação hipocolesterolêmica do óleo de palma, é a presença de outros componentes, ricos em propriedades nutricionais. Os mais importantes destes são os antioxidantes naturais tocotrienóis, a vitamina E e os carotenóides (principalmente alfa e beta-caroteno). Kamat \& Devasagayam ${ }^{21}$ estudaram a fração do óleo de palma rica em tocotrienóis e avaliaram seu potencial antioxidante in vitro; observaram que, em baixíssimas concentrações $(5 \mathrm{mM})$, estes compostos inibiam a peroxidação lipídica, tendo sido muito mais eficientes do que a vitamina $\mathrm{E}$.

Em conclusão, este estudo demonstrou que a substituição, na dieta, da gordura hidrogenada pelo óleo de palma, desde a lactação até a idade jovem, em ratos machos, altera o metabolismo lipídico e reduz, de forma efetiva, a concentração plasmática de triacilgliceróis e colesterol. Entretanto, altera a taxa lipogênica do tecido adiposo branco, ocasionando, após um período longo de tratamento (seis semanas e meia), elevação no conteúdo de gordura nos tecidos adiposos, no peso corporal, bem como na adiposidade dos animais.

\section{RE FER Ê N CIAS}

1. Mesink RP, Katan MB. Effect of dietary trans fatty acids on high-density and low-density lipoprotein cholesterol levels in healthy subjects. N Engl J Med. 1990; 323(7):439-45.

2. Troisi R, Willet WE, Weiss S. Trans-fatty acid intake in relation to lipid concentrations in adult men. Am J Clin Nutr. 1992; 56(6):1019-24. 
3. Hu FB, Sacks F, Willett WC. Dietary fats and prevention of cardiovascular disease. Patient compliance should have been considered. BMJ. 2001; 323(7319):1001-2.

4. Muller H, Jordal O, Kierulf $P$, Kirkhus B, Pederson J. Replacement of partially hydrogenated soybean oil by palm oil in margarine without unfavorable effects on serum lipoproteins. Lipids. 1998; 33(9):879-87.

5. Muller H, Seljeflot I, Solvoll K, Pederse J. Partially hydrogenated soybean oil reduces postprandial T$\mathrm{Pa}$ activity compared with palm oil. Atherosclerosis. 2001; 155(2):467-76.

6. Reeves PG, Neilesen FH, Fahey GC. American Institute of Nutrition (AIN). Purified Rodent Diets. J Nutr. 1993;123(11):1939-51.

7. Lepage G, Roy CC. Direct transesterification of all classes of lipid in on-step reaction. J Lipid Res. 1986; 27(1):114-20.

8. Robinson AM, Williamson DH. Comparison of glucose metabolism in the lactating mammary of the rat in vivo and in vitro: Effects of starvation, prolactin or insulin deficiency. Biochem J. 1997; 164:153-9.

9. Stansbie D, Browsey RW, Crettaz M, Demton RM. Acute effects in vivo of anti-insulin serum on rates of fatty acids synthesis and activities of acetyl-Coenzyme A Carboxilase and pyruvate dehydrogenase in liver and epididymal adipose tissue of fed rats. Biochem J. 1976; 160(2): 413-16.

10. Khalil MS, Hanson CF, Owens FN. Lipids sources differ in calorific value for growing rats. Nutr Res. 1992; 12:407-18.

11. Hariharan K, Purushothama S, Raina PL. Studies on red palm oil: Effect of partial supplementation of saturated fats upon lipids and lipoproteins. Nutrition Res. 1996; 8:1381-92.

12. Miyazawa T, Rebhung F, Fujimoto K, Kaneda T. Soy bean oil supplementation improves growth and prevents docosapentaenoic acid (C22:5 n-6) accumulation in tissues of rats fed palm oil diet. Biasci Biotech Biochem. 1994; 58:1794-8.

13. Honstra G. Essential fatty acids in mother and their neonates. Am J Nutr. 2000; 71(Suppl): S126-9.

14. Koletzko B. Trans fatty acids may impair biosynthesis of long chain polyunsaturates and growth in man. Acta Paediatr. 1992; 81(4): 302-6.

15. Herrera E. Formación de grasas: biosíntesis de ácidos grasos y triacilglicéridos. In: Herrera E, editor. Bioquímica: Aspectos estructurales y vias metabólicas. Madrid: Interamericana; 1991. p.591-614.

16. Cottrell RC. Introduction: Nutritional aspects of palm oil. Am J Clin Nutr. 1991; 53(4 Suppl): S989-1009.

17. Khosla P, Sundram K. Effects of dietary fatty acid composition on plasma cholesterol. Prog Lipid Res. 1996; 35(2):93-132.

18. Dougherty RM, Allman MA, lacono JM. Effects of diets containing high or low amounts of stearic acid on plasma lipoprotein fractions and fecal fatty acid excretion of men. Am J Clin Nutr. 1995; 61(5):1120-8.

19. Kris-Etherton Pm, Yu S. Individual fatty acid effects on plasma lipids and lipoproteins: Human Studies. Am J Clin Nutr. 1997; 65(5 Suppl):S1628-44.

20. Chandrasekharan N. Changing concepts in lipid nutrition in health and disease. Med J Malaysia. 1999; 54(3):408-27.

21. Kamat JP, Devasagayam TP. Tocotrienols from palm oil as potent inhibitors of lipid peroxidation and protein oxidation in rat brain mitochondria. Neurosci Lett. 1995; 195(3):179-82.

Recebido para publicação em 17 de setembro de 2003 e aceito em 4 de janeiro de 2004. 